OPEN ACCESS

Edited by:

Chuanlun Zhang,

Tongji University, China

Reviewed by:

Laura Villanueva,

Royal Netherlands Institute for Sea

Research, Netherlands

Meng Li,

Shenzhen University, China

*Correspondence:

Takuro Nunoura

takuron@jamstec.go.jp

Specialty section: This article was submitted to

Aquatic Microbiology,

a section of the journal

Frontiers in Microbiology

Received: 20 May 2016

Accepted: 29 July 2016

Published: 10 August 2016

Citation:

Nunoura T, Hirai $M$, Yoshida-Takashima Y, Nishizawa M,

Kawagucci S, Yokokawa $T$,

Miyazaki J, Koide O, Makita H, Takaki Y, Sunamura M and Takai $K$

(2016) Distribution and Niche

Separation of Planktonic Microbial

Communities in the Water Columns from the Surface to the Hadal Waters of the Japan Trench under

the Eutrophic Ocean.

Front. Microbiol. 7:1261.

doi: 10.3389/fmicb.2016.01261

\section{Distribution and Niche Separation of Planktonic Microbial Communities in the Water Columns from the Surface to the Hadal Waters of the Japan Trench under the Eutrophic Ocean}

\author{
Takuro Nunoura $^{1 *}$, Miho Hirai', Yukari Yoshida-Takashima², Manabu Nishizawa², \\ Shinsuke Kawagucci², Taichi Yokokawa' ${ }^{1}$, Junichi Miyazaki², Osamu Koide', \\ Hiroko Makita ${ }^{2}$, Yoshihiro Takaki ${ }^{1,2}$, Michinari Sunamura $^{3}$ and Ken Takai ${ }^{2}$ \\ ${ }^{1}$ Marine Functional Biology Group, Research and Development Center for Marine Biosciences, Japan Agency for \\ Marine-Earth Science and Technology, Yokosuka, Japan, ${ }^{2}$ Department of Subsurface Geobiological Analysis and Research, \\ Japan Agency for Marine-Earth Science and Technology, Yokosuka, Japan, ${ }^{3}$ Department of Earth and Planetary Science, \\ The University of Tokyo, Tokyo, Japan
}

The Japan Trench is located under the eutrophic Northwestern Pacific while the Mariana Trench that harbors the unique hadal planktonic biosphere is located under the oligotrophic Pacific. Water samples from the sea surface to just above the seafloor at a total of 11 stations including a trench axis station, were investigated several months after the Tohoku Earthquake in March 2011. High turbidity zones in deep waters were observed at most of the sampling stations. The small subunit (SSU) rRNA gene community structures in the hadal waters (water depths below $6000 \mathrm{~m}$ ) at the trench axis station were distinct from those in the overlying meso-, bathy and abyssopelagic waters (water depths between 200 and 1000 m, 1000 and 4000 m, and 4000 and $6000 \mathrm{~m}$, respectively), although the SSU rRNA gene sequences suggested that potential heterotrophic bacteria dominated in all of the waters. Potential niche separation of nitrifiers, including ammonia-oxidizing archaea (AOA), was revealed by quantitative PCR analyses. It seems likely that Nitrosopumilus-like AOAs respond to a high flux of electron donors and dominate in several zones of water columns including shallow and very deep waters. This study highlights the effects of suspended organic matter, as induced by seafloor deformation, on microbial communities in deep waters and confirm the occurrence of the distinctive hadal biosphere in global trench environments hypothesized in the previous study.

Keywords: hadal, trench, nitrification, deep ocean, niche separation

\section{INTRODUCTION}

Hadal oceans at water depths of below $6000 \mathrm{~m}$ are composed almost exclusively of trenches and are one of the least-explored biospheres on Earth. Trench environments are hydro topographically isolated from upper oceans, and exhibit elevated hydrostatic pressure, whereas the other physical and chemical conditions, such as temperature, salinity, dissolved oxygen (DO), and nutrient 
concentrations, in the hadal waters are comparable to those in abyssal oceans at a water depth of between 4000 and $6000 \mathrm{~m}$ (Mantyla and Reid, 1978; Nozaki et al., 1998; Taira et al., 2004, 2005; Jamieson et al., 2010). Currently the existence of the "hadal biosphere" has been demonstrated for both benthic and planktonic microbial ecosystems in the Challenger Deep of the Mariana Trench (Glud et al., 2013; Nunoura et al., 2015). The hadal benthic microbial ecosystems in the Mariana Trench have been characterized by their higher carbon turnover and oxygen consumption rates than those in adjacent abyssal plain sediments (Glud et al., 2013). Planktonic hadal microbial communities harbor relatively higher abundances of heterotrophic bacterial populations and nitrifiers populations probably adapting higher fluxes of electron donors as compared with the communities associated with the overlying abyssal water masses (Nunoura et al., 2015). The hadal biosphere and biogeochemical cycles are likely constrained primarily by the trench geomorphology and by the endogenous recycling and input of organic matter associated with occasional seafloor deformation (landslides and turbulent sediments) in the vast trench slope area (Glud et al., 2013; Ichino et al., 2015; Nunoura et al., 2015). Nevertheless, such a distinctive hadal microbial ecosystem has been found only in the Mariana Trench, and the following points should be addressed further: whether the distinctive hadal microbial ecosystem is widespread in the global trench environments; whether the members and functions of hadal microbial communities are common in trenches under geologically and oceanographically different settings or specific in each hadal environment; and if different, what types of factors constrain the compositions and functions of hadal microbial communities and how they are controlled.

The Japan Trench is geologically and oceanographically distinct from the Mariana Trench and is a suitable environment for the comparative study of the hadal biosphere. This trench, with a maximum depth of approximately $8000 \mathrm{~m}$, is located in the eutrophic region of the Northwestern Pacific and is close to Honshu Island, Japan, whereas the Mariana Trench is located under the oligotrophic equatorial Pacific, far from continental margins. In March 2011, the Tohoku Earthquake (M9) occurred at the Japan Trench, thus providing an opportunity to investigate the geochemical and biological effects of disturbed seafloor in coastal to hadal waters and seafloor environments (Kawagucci et al., 2012; Noguchi et al., 2012; Arai et al., 2013; Oguri et al., 2013; Kitahashi et al., 2014; Sano et al., 2014; Nomaki et al., 2016). During the post-earthquake investigations of the Japan Trench, it became evident that some of the abyssal and bathyal waters were highly affected by the suspended sediments at 36 days after the M9 earthquake: the microbial communities in these turbid waters were characterized by a greater abundance of microbial cells and greater enrichments of heterotrophic bacterial components compared to the abyssal and bathyal waters without the influence of suspended sediments (Kawagucci et al., 2012). Indeed, this finding has provided important insight into predicting the driving forces for the formation and development of hadal microbial communities in the Mariana Trench, as described in a later study (Nunoura et al., 2015). However, previous postearthquake investigations in the Japan Trench region did not cover microbial communities associated with hadal waters, and the effects of suspended sediments on the planktonic microbial community were addressed by using only small subunit (SSU) rRNA gene sequencing analysis (Kawagucci et al., 2012).

Therefore, in this study, we attempted to characterize the spatial distribution of planktonic microbial communities associated with surface to hadal waters in the eutrophic Japan Trench to confirm the geochemical gradients across the different depths. Especially, we examined the potential niche separation of nitrifiers' communities to understand the effects of organic matter originating from landslides and/or turbulent sediments and the surface primary production on the deep-water microbial communities. The $\mathrm{NH}_{4}{ }^{+}$flux serves as an excellent biogeochemical tracer of the decomposition of nitrogenous organic matter supplied from sediments and surface primary production, and the niche separation of nitrifiers may be tightly associated with the availability of electron donors (Blackburne et al., 2007; Martens-Habbena et al., 2009; Sintes et al., 2013).

\section{MATERIALS AND METHODS}

\section{Sample Collection}

The Japan Trench is located along northeastern Japan and at the northwestern margin of the Pacific Plate. The seawater samples used in this study were obtained by vertical hydrocasts of the CTD-CMS (Conductivity Temperature Depth profiler with a Carousel Multiple Sampling system) during a total of three cruises in 2011 after the M9.0 earthquake, and the sampling stations and water depths are summarized in Supplementary Table S1 and Supplementary Figure S1. Hydrocasts at stations $\mathrm{N} 1, \mathrm{~N} 2, \mathrm{~N} 3, \mathrm{R}$, and JKEO were conducted in April during the R/V Mirai MR11-03 cruise (JAMSTEC; Kawagucci et al., 2012). Hydrocasts at stations E, F, and G were conducted during the YK11-E03 cruise (JAMSTEC) of in May and those at stations 2, $3,4,5$, and 6 were conducted during the YK11-E04 cruise in June were carried out by using R/V Yokosuka.

The wired CTD-CMS system of the MR11-03 cruise included a CTD (SBE9 Plus, Sea-Bird Electronics), a CMS (SBE32, SeaBird Electronics), 36 Niskin-X bottles (12-liter type, General Oceanics), and a light transmissometer (C-star 25-cm lightpath type, WET Lab). The Light Transmission Anomaly (LTA), calculated from the difference between the in situ light transmission value (Tr: \%) and the value of the transparent layer at intermediate depth for each hydrocast, is used to describe deep-sea water turbidity (Kawagucci et al., 2012). The CTD-CMS system of the YK11-E03 and YK11-E04 cruises consisted of a CTD (SBE11 Plus, Sea-Bird Electronics), a CMS (SBE32, SeaBird Electronics), and 12 Niskin-X bottles (12-liter type, General Oceanics). A turbidity sensor (ATU6W-CMP, JFE Advantech) was applied to some of the casts during the YK11-E03 and YK11-E04 cruises.

Seawater samples taken by the Niskin bottles and were subsampled immediately after recovery onboard for geochemical and microbiological analyses. The concentrations of $\mathrm{DO}, \mathrm{NO}_{3}{ }^{-}$, $\mathrm{NO}_{2}{ }^{-}, \mathrm{Si}$, and $\mathrm{PO}_{4}{ }^{-}$as analyzed on board in the case of the MR11-03 cruise were obtained from the Data Research System 
for Whole Cruise Information in JAMSTEC (DARWIN) ${ }^{1}$. The seawater samples obtained during the YK11-E03 and YK11-E04 cruises were filtrated by a Millex filter unit with $0.22 \mu \mathrm{m}$ pore size (Millipore) and stored at $-20^{\circ} \mathrm{C}$ for geochemical analyses. The concentrations of $\mathrm{NO}_{3}{ }^{-}, \mathrm{NO}_{2}{ }^{-}$, and $\mathrm{PO}_{4}{ }^{-}$were then analyzed spectrophotometrically using an automated QuAAtro 2-HR analyzer (BL TEC, Japan) at an onshore laboratory in the YK11-E03 and YK11-E04 cruises.

Samples for cell counting were fixed with neutralized formalin (final conc. $3.7 \%$ formaldehyde) and stored at $-80^{\circ} \mathrm{C}$. Samples for virus counting were fixed with glutaraldehyde (final conc. $1 \%$ ), frozen by liquid nitrogen and stored at $-80^{\circ} \mathrm{C}$. For molecular analyses, microbial cells in 2-3 L of each sample were filtered on $47 \mathrm{~mm}$ cellulose acetate filter $(0.22 \mu \mathrm{m}$ pore size, Advantech) and stored at $-80^{\circ} \mathrm{C}$.

\section{Cell and Viral Particle Counting}

For cell counting, each sample was filtered onto a $0.2-\mu \mathrm{m}$ pore-size Isopore membrane filter (Millipore, Bedford, MA, USA), after being stained with 4',6-diamidino-2-phenylindole (DAPI). The cells on these filters were counted with an Olympus BX51 fluorescence microscope (Olympus, Tokyo, Japan) at a magnification of $\times 1,500$. At least 400 cells per sample were counted in more than 20 randomly chosen fields in triplicate. Viral particle counts were performed with a FACSCalibur flow cytometer (Becton Dickinson, Franklin Lakes, NJ, USA) as described previously (Brussaard, 2009). Briefly, each sample was stained with SYBR Green I (at a final concentration of $0.5 \times 10^{-4}$ of the commercial stock; Thermo Fisher Scientific, Waltham, MA, USA) for $10 \mathrm{~min}$ at $80^{\circ} \mathrm{C}$. Yellowgreen fluorescent microspheres with a diameter of $1.0 \mu \mathrm{m}$ (FluoSpheres; Thermo Fisher Scientific) were used as internal standard. Viral particles were discriminated on plots of side scatter versus green fluorescence.

\section{DNA Extraction and Amplification}

Environmental DNA was extracted from the cells on a cellulose acetate membrane filter using a Soil DNA Isolation Kit (MoBio Lab, Carlsbad, CA, USA) with minor modification. Some of the environmental DNA was amplified using a REPLI-g Mini Kit (Qiagen Inc., Valencia, CA, USA) for molecular analyses as described below. Amplified DNA assemblages were digested by S1 nuclease (Invitrogen) prior to the following studies.

\section{Molecular Analyses of the SSU rRNA and Archaeal amoA Genes}

Prokaryotic SSU rRNA gene fragments were amplified with a primer set of 530F and 907R (Nunoura et al., 2012) from the original environmental DNA assemblages using LA Taq polymerase with GC buffer (Takara Bio, Otsu, Japan) as described previously. For archaeal amoA clone analysis, gene fragments were obtained with a primer set of Arch-amoAF/ArchamoAR (Francis et al., 2005) using LA Taq polymerase (Takara Bio) from the amplified environmental DNA assemblages. The

${ }^{1}$ http://www.godac.jamstec.go.jp/darwin/e amplification conditions and primer sequences for each PCR amplification are summarized in Supplementary Table S2.

In the clone analyses, the amplified DNA fragments were cloned into the pCR2.1 vector (Invitrogen) and the clone libraries were constructed. The inserts were directly sequenced with the M13M4 primer using a genetic analyzer ABI3730xl with Big Dye ver. 3.1. The SSU rRNA and archaeal amoA gene sequences with $>97 \%$ identity were assigned as the same clone type (phylotype) using Sequencher v 5 (Gene Codes, Ann Arbor, MI, USA) and GENETYX-MAC ver. 15 (GENETYX, Tokyo, Japan). Potential chimera sequences were manually detected using GENETYXMAC ver. 15 and blast analysis and were excluded from the further analyses. Also excluded were sequences that were closely related to the potential contaminants, which belong to the genera that are typically found in soil and the human body and that are often detected in the previous negative control experiments of PCR in our lab, such as Bradyrhizobium, Brevundimonas, Burkholderiaceae, Delftia, Erythrobacter, Lactococcus, Legionella, Methylobacterium, Mycobacterium, Neisseria, Novosphingobium, Propionibacterium, Sphingobium, Sphingomonas, Sphingopyxis, Staphylococcus, Stenotrophomonas, and Streptococcus.

After omitting potential chimeric sequences and potential experimental contamination sequences, all of the SSU rRNA gene sequences obtained in this study were compared using the UniFrac program (Lozupone et al., 2006). An alignment of each SSU rRNA gene clone library was constructed using the SINA alignment service ${ }^{2}$ (Pruesse et al., 2012). A phylogenetic tree of the SSU rRNA gene sequences obtained in this study was constructed by the neighbor-joining method using Clustal $\mathrm{X}$ ver. 2.0 (Larkin et al., 2007), and a principal component analysis (PCA) was carried out with UniFrac. Representative SSU rRNA gene sequences were aligned and phylogenetically classified into certain taxonomic units using ARB (Yilmaz et al., 2014). A phylogenetic tree of the thaumarchaeal SSU rRNA gene was constructed with Clustal X based on the unambiguous nucleotide positions. Representative amoA sequences were automatically aligned with closely related nucleotide sequences, and then, a phylogenetic tree was constructed by using Clustal X.

\section{Quantitative PCR Analyses}

The primers, probes and components of the standard mixture used for the quantitative PCR analyses are summarized in Supplementary Table S2. The abundance of each gene was quantified as an average of the duplicate or triplicate analyses. A 7500 Real Time PCR System (Applied Biosystems) was used for the all of the assays. The original DNA assemblages were only used for the quantification of the prokaryotic and archaeal SSU rRNA genes, and the amplified DNA assemblages described above were used for the quantification of other genes. The abundance of nitrifier genes in each water sample was estimated from the relative abundance of the archaeal SSU rRNA gene and the respective gene in the amplified DNA assemblages.

The quantification of the archaeal and prokaryotic SSU rRNA genes was performed using primer and probe sets described previously (Takai and Horikoshi, 2000) with minor modifications

${ }^{2}$ http://www.arb-silva.de/aligner/ 
as described below. Premix Ex Taq ${ }^{\mathrm{TM}}$ (Perfect Real Time; Takara Bio) was used for the master mix solution, and a probe was added with a final concentration of $0.2 \mathrm{pmol} / \mu \mathrm{l}$ in PCR reaction solution. The SSU rRNA gene mixtures for obtaining standard curves for each experiment were prepared as follows: a mixture of Haloarcula japonica JCM7785, Sulfurisphaera sp. (Takai and Horikoshi, 2000), Thermococcus sp., "Ca. Caldiarchaeum subterraneum" (Nunoura et al., 2011), and MGI $\alpha$ subgroup pMC1A11 (Takai and Horikoshi, 1999) for the archaeal SSU rRNA gene and that of Haloarcula japonica, Thermococcus sp., MGI $\alpha$ subgroup pMC1A11, Shewanella violacea JCM10179 and Alkaliphilus transvaalensis $\mathrm{SAGM}^{\mathrm{T}}$ for the prokaryotic SSU rRNA gene. The detection and quantification of nitrifiers were assessed using the amplified environmental DNA assemblages.

Detections of the alpha- and betaproteobacterial $n \times r A$ and alpha- and gammaproteobacterial $a m o A$ were performed using Ex Taq polymerase (Takara Bio) with an $\mathrm{Mg}^{2+}$ buffer as described previously (Purkhold et al., 2000; Wertz et al., 2008; Nunoura et al., 2013) (Supplementary Table S2). The abundance of the Nitrospina and Nitrospira SSU rRNA genes was also examined according to the methods described previously (Graham et al., 2007; Nunoura et al., 2013). To identify the group-specific distribution of each archaeal amoA gene group, we modified primer sets used in our previous study (Nunoura et al., 2015) and constructed novel primer sets based on the archaeal amo $A$ gene sequences obtained in this study as follows. The nucleotide sequence alignments of the archaeal $a m o A$ gene were constructed with Clustal X ver. 2.0, and we designed primers that specifically matched the $a m o A$ sequences in the individual groups $\mathrm{A}, \mathrm{Ba}$, $\mathrm{Bb}$, and $\mathrm{C} / \mathrm{D}$ (Supplementary Table S2). For the preparation of quantitative PCR mixtures for specific SSU rRNA gene and functional genes, we applied qPCR Quick GoldStar Mastermix Plus (Eurogentec, Seraing, Belgium) for the SSU rRNA genes of Nitrospira and SYBR Premix Ex Taq II (Takara Bio) for the amoA genes and the Nitrospina SSU rRNA genes (Stephen et al., 1999; Nunoura et al., 2013, 2015). The amplified products from quantitative PCR using SYBR Premix reagent were confirmed by agarose gel electrophoresis. Especially in the archaeal amoA genes, amplification specificity was confirmed by clone analysis for the amplicons from several sample depths.

\section{Accession Numbers}

The SSU rRNA and archaeal amoA gene sequences obtained in this study were deposited in the DDBJ/EMBL/GenBank database under the following accession numbers; LC087228-LC087916.

\section{RESULTS}

\section{Environmental Conditions}

Conductivity Temperature Depth casts were conducted for a total of 10 stations above the Japan Trench and one station on the abyssal plain in April, May, and June 2011, which corresponded to 36-46, 75-76, and 95-96 days after the Tohoku Earthquake, respectively (Supplementary Table S1; Supplementary Figure S1). Seasonal differences in the temperature and salinity profiles were observed in shallow waters but were not found in waters deeper than 300 m below sea surface (mbs; Supplementary Figure S2). The temperature and salinity profiles between 100 and $600 \mathrm{mbs}$ in the Japan Trench were disturbed because of the mixing of cold and warm currents (Kouketsu et al., 2005), whereas those at a JKEO abyssal plain station (Cronin et al., 2008) were relatively smooth (Supplementary Figure S2). The temperature and salinity below the bathypelagic zone were very similar to each other, and neither geomorphology nor deep-sea currents seemed to affect the depth profiles of temperature and salinity.

Light transmission anomalies in deep waters, which can be a signature of the turbulent diffusion of sediments associated with earthquake-induced seafloor deformation, were determined in the CTD casts during the MR11-03 cruise in April (Kawagucci et al., 2012; Noguchi et al., 2012). During the cruises YK11-E03 and E04, turbidity instead of light transmission anomalies was determined, except for the CTD casts at trench axis station E (Supplementary Figure S3) because the water depth of trench axis station E exceeded the pressure limit of the turbidity sensor. At all of the stations, including station JKEO, increased turbidity was observed just above the seafloor. The higher turbidity in shallow waters was likely due to the greater biomass associated with the vigorous primary production in this region, and the peaks of turbidity in abyssal and bathyal waters at some of the stations may have reflected flows of turbulent sediments associated with earthquake-induced seafloor deformation (Kawagucci et al., 2012).

No apparent anomaly was observed in the profiles of the DO and nutrient concentrations (Supplementary Figure S4). Nitrate at the sea surface was depleted, and nitrate concentrations greater than $40 \mu \mathrm{mol} / \mathrm{kg}$ were observed from 600 to $2000 \mathrm{mbs}$. The nitrate concentration in bathyal and hadal waters was constant within a range of 35 to $37 \mu \mathrm{mol} / \mathrm{kg}$. The nitrite concentrations at station JKEO were greater than $0.2 \mu \mathrm{mol} / \mathrm{kg}$ in shallow waters above $150 \mathrm{mbs}$, whereas nitrite at the trench axis station $\mathrm{E}$ was almost depleted $(<0.1 \mu \mathrm{mol} / \mathrm{kg})$ in shallow water except for at a depth of $200 \mathrm{mbs}$. Nitrite was depleted below $200 \mathrm{mbs}$ at all of the stations.

\section{Microbial and Viral Abundance}

The abundances of microbial cells and viral particles (large virus-like particles that can be detected by flow cytometry) in the water samples was evaluated by direct cell counting under a fluorescence microscope and by viral counting using flow cytometry, respectively (Figure 1). An overall trend was that the abundance of microbial cells and viral particles decreased with increasing depth to approximately $3000 \mathrm{mbs}$ and was relatively constant below this depth. The maximum cell and viral abundance was $5.7 \times 10^{5}$ cells $/ \mathrm{ml}$ and $2.9 \times 10^{7}$ particles $/ \mathrm{ml}$ in the surface water at station E. Virus prokaryote ratio (VPR) values above $2000 \mathrm{mbs}$ were relatively constant, and most of them ranged from 20 to 60 , but the VPR values below $2000 \mathrm{mbs}$ were higher and more variable than those in the shallower waters above $2000 \mathrm{mbs}$ and ranged from 33 to 256. Variable patterns in cell and viral abundance and VPR value were observed in many of the water samples close to the seafloor. In particular, the cell abundances in the bathypelagic waters at station N2 and the abyssal waters at station $\mathrm{R}$ collected 36 days after the earthquake, 

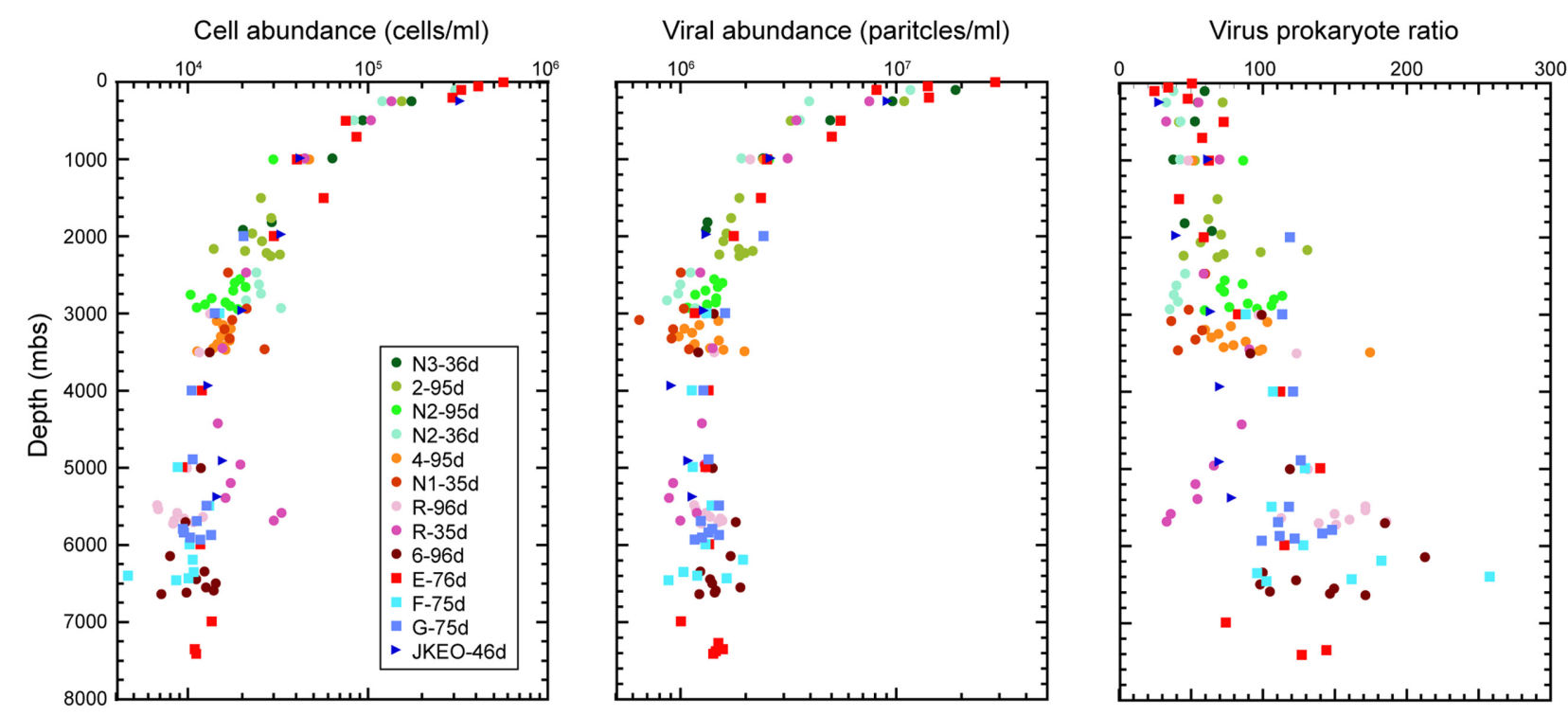

FIGURE 1 | Microbial cell and viral abundance and virus-prokaryote ratio throughout the water columns in the Japan Trench region. Each color indicates the sampling stations and the sampling time (days) after the Tohoku Earthquake on March 11, 2011.

was higher than that at stations 3 and 5, respectively, obtained 96 days after the earthquake (Kawagucci et al., 2012); the viral abundances exhibited the opposite trend.

The abundance of prokaryotic communities was also evaluated by quantitative PCR analysis for prokaryotic and archaeal SSU rRNA genes in samples from a total of eight stations (Figure 2; Supplementary Table S3). The relative abundance of the archaeal SSU rRNA gene in the entire prokaryotic SSU rRNA gene assemblage was very low in surface waters (4\%), and the archaeal SSU rRNA gene populations dominated in the entire prokaryotic SSU rRNA gene assemblages in deep-water zones (Figure 2). However, at depths close to the seafloor, the relative abundance of the archaeal SSU rRNA gene in the entire prokaryotic SSU rRNA gene assemblage decreased (Figure 2). In addition, the bathyal to abyssal waters at stations $F$ and $G$, which had higher turbidity, showed relatively low archaeal rRNA gene populations compared to those of abyssal and bathyal waters at trench axis station E. In all of the stations, the highest relative abundance of the archaeal SSU rRNA gene was found in the mesopelagic waters.

\section{Distribution and Composition of SSU rRNA Gene Communities}

A prokaryotic SSU rRNA gene clone analysis was applied for environmental DNA assemblages from trench axis site station $\mathrm{E}$ (sea surface to hadal waters; 0-7404 mbs), station F on the eastern (ocean-side) slope (abyssal to hadal waters; 3992-6487 mbs) and station 2 on the western (continental-side) slope (mesopelagic to bathyal waters; 249-2250 mbs; Figure 3). No amplicons of negative control PCR amplification were observed in the gel electrophoresis, and a few sequences were identified as potential contaminants in the clone analysis. After removing potential contaminants and chimeras, a total of 2046 sequences from 23 libraries were analyzed: 1372 sequences from the trench axis site at station E (each $81-112$ sequence from 15 libraries), 418 sequences from the continental slope site at station 2 (each 74-88 sequence from five libraries) and 256 sequences from the ocean slope site at station $\mathrm{F}$ (each $82-89$ sequence from three libraries; Supplementary Table S4).

Through the water column of the trench axis station E, potential heterotrophic taxa such as Bacteroidetes, Planctomycetes, and heterotrophic groups of Gammaproteobacteria, were detected as the predominant populations in the SSU rRNA gene clone libraries (Figure 3). The SSU rRNA gene community composition in the surface water was dominated by the SSU rRNA gene of Cyanobacteria and chloroplasts. Thaumarchaeota was not detected and "Candidatus (Ca.) Marinimicrobia" (SAR406) was found as a minor population in the clone library. The SSU rRNA gene community at $302 \mathrm{mbs}$ showed the highest abundance of Thaumarchaeota and the absence of heterotrophic lineages of Gammaproteobacteria. Alphaproteobacterial sequences other than SAR11 phylotypes dominated in the SSU rRNA gene communities associated with waters above $200 \mathrm{~m}$ and at hadal depths; however, these sequences were detected as relatively minor populations in the mesopelagic, bathyal, and abyssal waters. Except in the surface water, the Thaumarchaeota phylotypes were predominant populations, whereas the Cyanobacteria and chloroplast sequences were minor populations throughout the water column. Moreover, potential chemolithotrophic lineages, such as SAR324 (Chitsaz et al., 2011; Swan et al., 2011; Sheik et al., 2014), Nitrospina (Spieck et al., 2014), and sulfur-oxidizing groups of Gammaproteobacteria were also detected. The SAR324 phylotypes represented one of the dominant populations in the mesopelagic, abyssal, and bathyal waters, but became a minor population in the hadal waters. The Nitrospinae phylotypes emerged in the SSU rRNA 


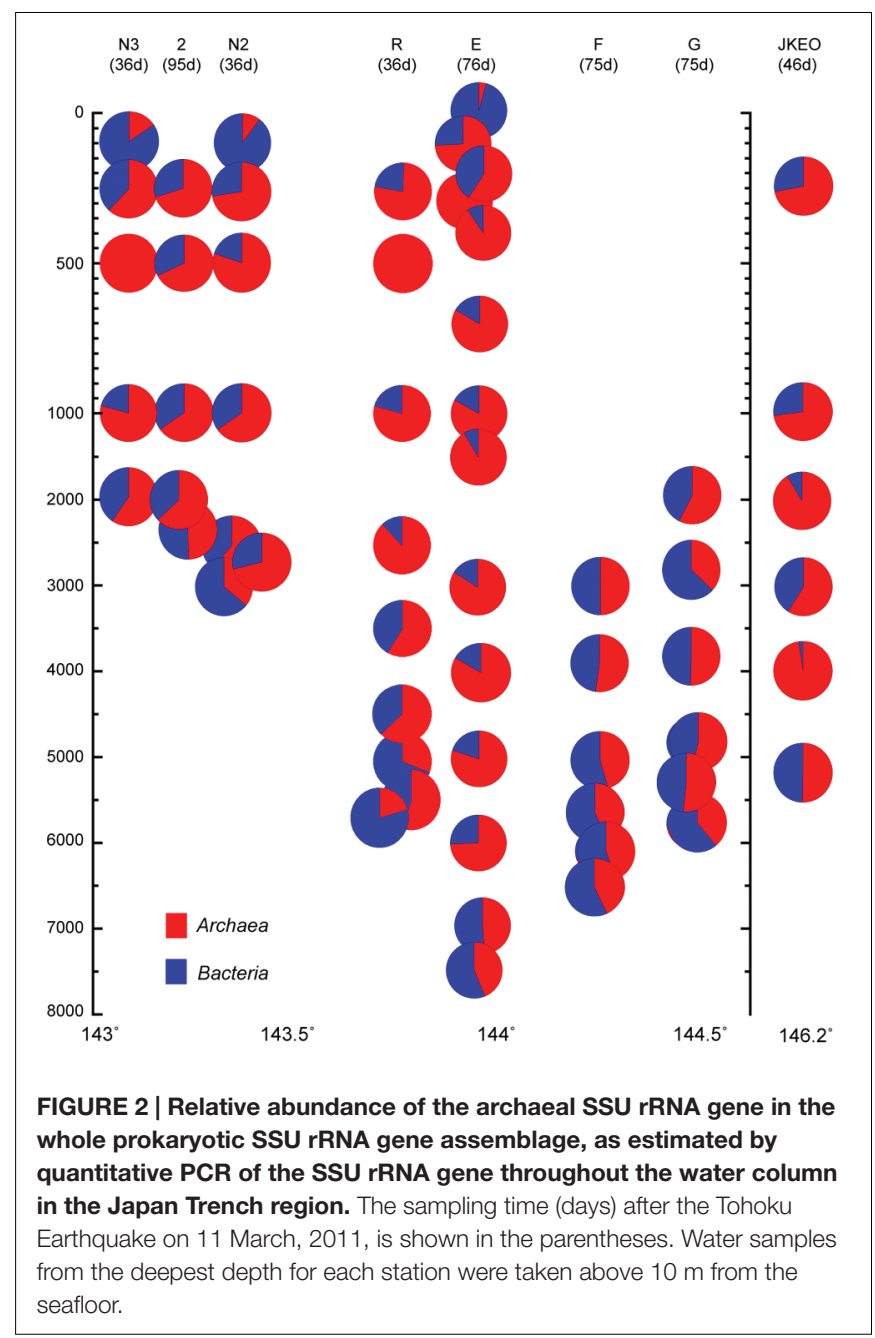

gene communities below $100 \mathrm{mbs}$ and particularly dominated the SSU rRNA gene communities at depths between 100 and 300 mbs. In addition, the gammaproteobacterial sulfur oxidizers represented by SUP05 and Agg47 (Swan et al., 2011; Marshall and Morris, 2012) were detected throughout the water column, and notably, the relative abundance of SUP05 group increased in the hadal waters. Predominance of heterotrophic Halomonas and Pseudomonas population found in the waters below $9000 \mathrm{mbs}$ in the Mariana Trench (Nunoura et al., 2015) did not occur in this station.

The relative abundance of archaeal sequences in the clone libraries from trench axis station E ranged from 19 to 55\%, except in the library of the surface water (1\%). The average abundance of archaeal SSU rRNA genes in the entire prokaryotic SSU rRNA gene populations as estimated by quantitative PCR was $43 \%$, except in the surface water. The archaeal abundance profiles that were obtained by the clone and QPCR analyses were similar $(R=0.92)$, although both analyses might be influenced by biases in PCR. Potential ammonia-oxidizing Thaumarchaeota phylotypes predominated in most of the archaeal SSU rRNA gene communities. The MGI group $\alpha$ phylotypes represented the predominant population throughout the water column in shallower depths, except for at $300 \mathrm{mbs}$ and in abyssal waters (Supplementary Figures S5 and S6), and MGI group $\beta$ phylotypes were also the abundant population, except at $202 \mathrm{mbs}$. Higher abundances of group $\alpha$ than group $\beta$ phylotypes were found in the shallow waters at 101,202 , and $403 \mathrm{mbs}$ and in hadal waters.

All of the SSU rRNA gene communities obtained in this study were compared using the UniFrac principal coordination analysis (PCA) and Jackknife clustering analysis. In the PCA analysis, the SSU rRNA gene communities from continental slope station 2 shared unique positions compared to those from the other two stations E and F (Supplementary Figure S7). The SSU rRNA gene phylotype compositions from station 2 harbored relatively higher abundances of the potential heterotrophic Bacteroidetes and Gammaproteobacteria populations than those at the other sites. The analysis also presented a similarity of the SSU rRNA phylotype compositions between the hadal waters of station E (6989 and $7407 \mathrm{mbs}$ ) and the abyssal to hadal waters (5487 and 6487 mbs) from station F, whereas those in the abyssal waters (4989 and $5988 \mathrm{mbs}$ ) from station E were more similar to those in the bathyal and mesopelagic waters of the same site (1001$3996 \mathrm{~m}$ ). In the Jackknife clustering, two distinct branches and a major cluster were identified (Figure 4). The two distinct branches were the SSU rRNA gene communities in the surface water and the shallow water of $300 \mathrm{~m}$ at station E. In the major cluster, a distinctive subcluster constituted each water mass of the lower photic zone (101 and $202 \mathrm{mbs}$ ), the upper mesopelagic zone (250-500 mbs), the lower mesopelagic, bathyal, and abyssal zones (700-6000 mbs), and the hadal zone (6986 and $7407 \mathrm{mbs}$ ).

\section{Detection and Quantification of Nitrifiers' Populations}

To clarify the distribution and niche separation of potential ammonia oxidizers that respond to the availability/flux of ammonia/ammonium, the archaeal $a m o A$ gene community was investigated for the water column at trench axis station $\mathrm{E}$ by clone analysis, and subsequent quantitative PCR analyses for nitrifiers were conducted for a total of eight stations. In these analyses, the amplified environmental DNA was prepared as in the case of a previous study (Nunoura et al., 2015).

The archaeal amoA gene amplicons were successfully obtained from all of the samples, including surface water, and the clone analysis revealed the potential niche separation of AOA (Supplementary Figures S8 and S9; Supplementary Table S5). Group A amoA gene phylotypes dominated in the shallow waters from the sea surface to 1000 mbs. Group $\mathrm{Bb}$ and $\mathrm{Ba}$ phylotypes were detected as predominant populations in waters from 100 to $5000 \mathrm{mbs}$ and below $200 \mathrm{mbs}$, respectively. Group C and D phylotypes were detected below $4000 \mathrm{mbs}$ as relatively minor populations compared to the group Ba phylotypes. Groups A, $\mathrm{C}$, and $\mathrm{D}$ have previously been recognized as "high ammonia cluster" (HAC) and Groups $\mathrm{Ba}$ and $\mathrm{Bb}$ were also known as the "low ammonia cluster" (LAC) in the archaeal amoA gene classification (Sintes et al., 2013).

For the quantitative PCR of each archaeal amoA group, we modified the primer sequences because several mismatch 


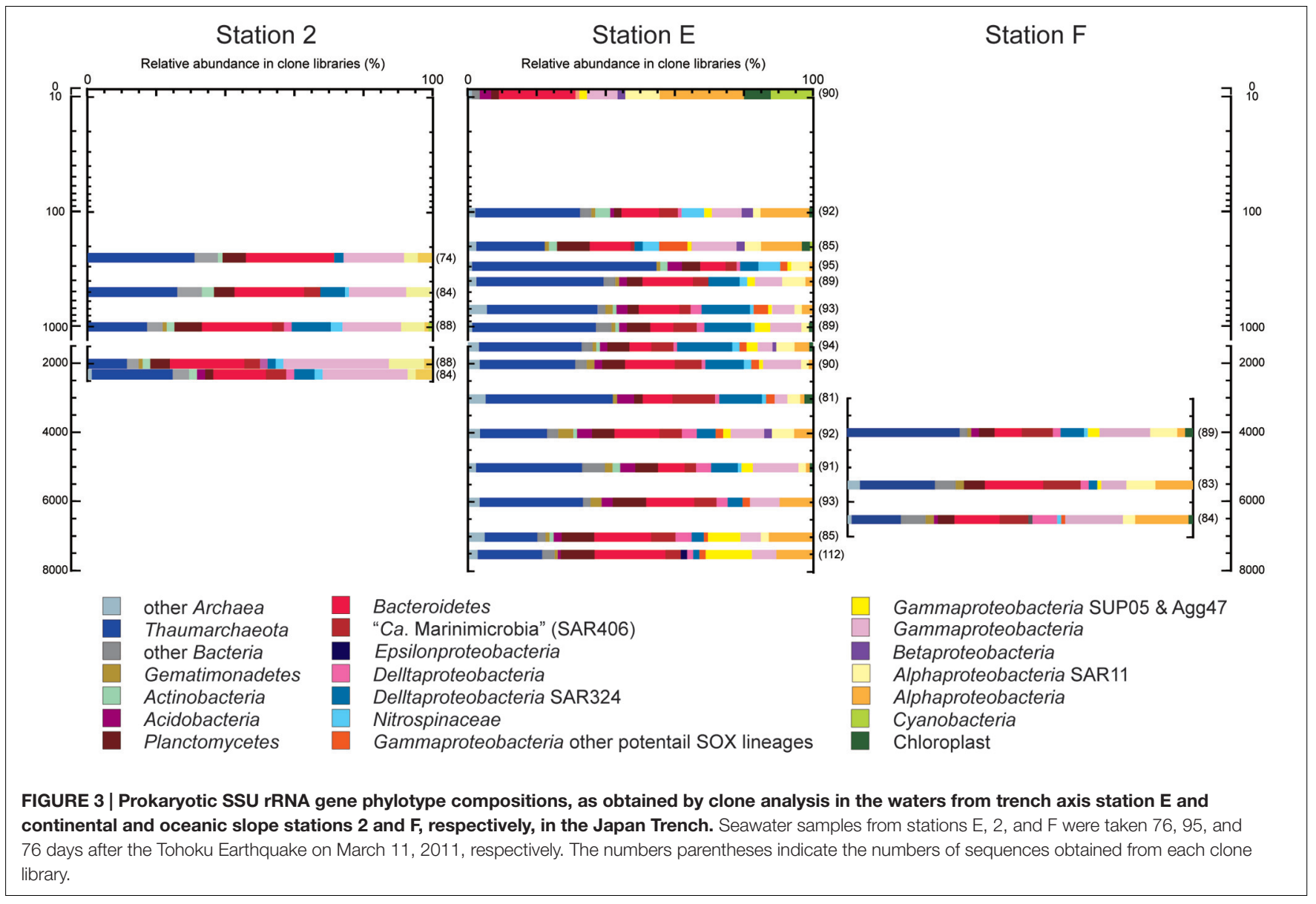

residues were found between the amo $A$ gene sequences found in this study and the group-specific primer sets for archaeal amoA gene groups $\mathrm{A}$ and $\mathrm{Ba}$ that have previously been reported (Nunoura et al., 2015). In addition, a primer set that quantified both groups $\mathrm{C}$ and $\mathrm{D}$ amoA gene phylotypes was newly constructed in this study (Supplementary Table S5). Quantitative PCR for amoA genes revealed the niche separation of ammonia oxidizers along the water column (Figure 5). Interestingly, no apparent seasonal variation was observed in the distribution pattern of amoA associated with shallow waters although the possible seasonal variation was found in the salinity and temperature profiles of the shallow waters. The ammoniaoxidizers community at $302 \mathrm{mbs}$ at station E was distinct from those associated with the shallow waters. The predominant ammonia-oxidizing groups in the waters above $500 \mathrm{mbs}$ were groups $\mathrm{C}$ and $\mathrm{D}$, and the predominant group in mesopelagic to bathyal waters was group $\mathrm{Ba}$. The relative abundance of groups $\mathrm{C}$ and $\mathrm{D}$ increased in the bathyal and hadal waters, and especially in the waters close to the seafloor (Figure 5). The greater abundance of group $\mathrm{Bb}$ was observed in deeper zones of mesopelagic and abyssal waters (500-3500 mbs; Figure 5). Betaproteobacterial $a m o A$ and group $\mathrm{A}$ archaeal $a m o A$ were found to be minor populations through the water column, whereas group A was detected as a predominant component in the clone analysis of the archaeal amoA gene (Supplementary
Figure S9). The preferred distribution of group A in relatively shallow waters has previously been reported (Beman et al., 2010; Santoro et al., 2015). In contrast, the relative abundance of betaproteobacterial amoA populations increased in the shallow waters and the waters near the sea bottom. The preferential incidence of the betaproteobacterial amoA populations in shallow waters was likely consistent with the detection of Nitrosospira in waters at 200 and $300 \mathrm{mbs}$ at station E based on the SSU rRNA gene clone analysis. The sum of the archaeal amoA copy number in the DNA assemblages below $100 \mathrm{mbs}$ was correlated with the archaeal SSU rRNA gene copy number in a ratio of 0.65 ( $R=0.91)$.

In a nitrite-oxidizing bacteria (NOB) population as estimated by quantitative PCR analyses, Nitrospina was detected as the predominant group, and Nitrospira was found to be a minor population throughout the depths and was absent in some of the samples (Supplementary Figure S10). The relative abundance of Nitrospira in the potential NOB population was less than $10 \%$ in most of the samples. Relatively higher abundance of Nitrospira was found in the shallow waters of station E, and in some of the bathyal and hadal waters. The gammaproteobacterial ammonia oxidizers and alpha- and gammaproteobacterial nitrite oxidizers (e.g., Nitrobacter and Nitrococcus, respectively) were not detected throughout the water column by conventional PCR amplification. 


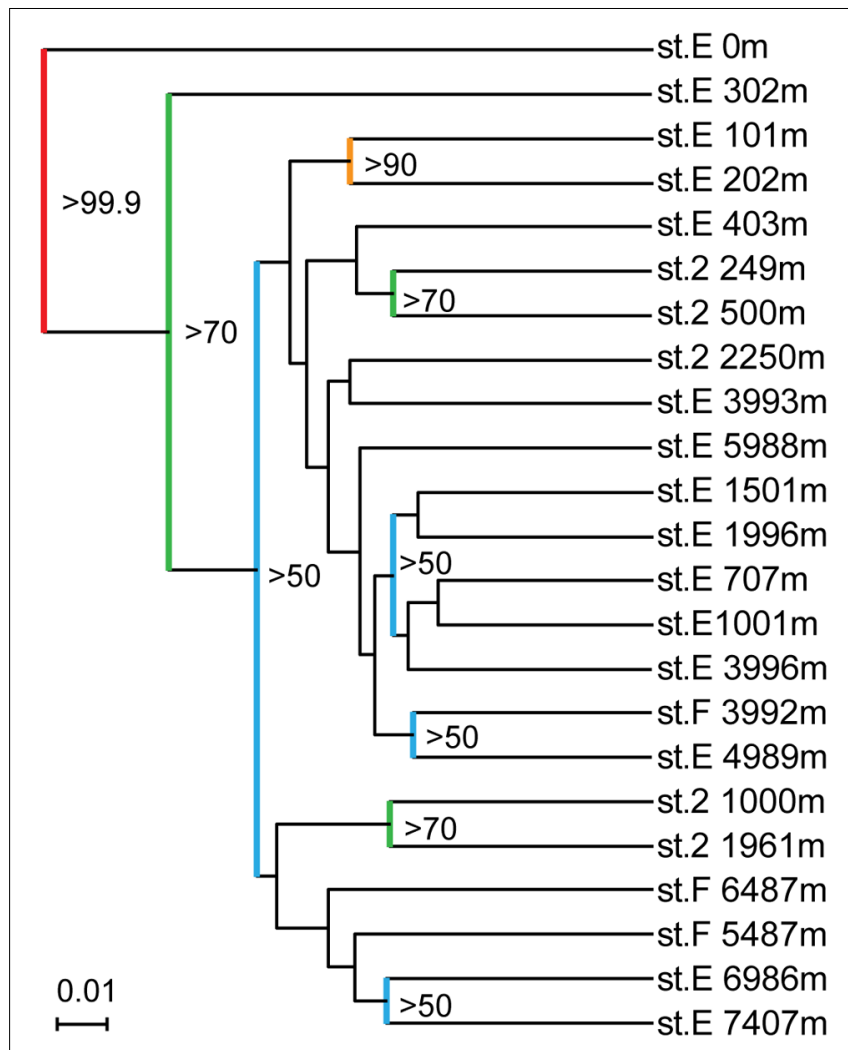

FIGURE 4 | Result of running Jackknife Environment Clusters of the SSU rRNA gene clone libraries obtained from the waters in the Japan Trench. Nodes recovered $99.9 \%$ of the time are red, $90-99.9 \%$ are orange, $70-90 \%$ are green, and $<50 \%$ are blue.

\section{DISCUSSION}

\section{Microbial Communities under Eutrophic Ocean}

A comparison of the SSU rRNA gene community structures and quantitative PCR analyses for nitrifiers has revealed both similarities and differences in the distribution patterns of microbial communities throughout the water column in the Japan Trench and Mariana Trench (Nunoura et al., 2015). The predominance of potential heterotrophic populations represented by Bacteroidetes and "Ca. Marinimicrobia” (SAR406) in the SSU rRNA gene communities was observed from the sea surface to hadal waters in the Japan Trench region (Figure 3), whereas the potential chemolithotrophic populations; SAR324 and MGI Thaumarchaeota, dominate the microbial communities in mesopelagic to abyssal waters in the Mariana Trench (Nunoura et al., 2015). The predominance of group $\alpha$ MGI in the shallow waters above $500 \mathrm{mbs}$ detected was found in the Japan Trench but not in the Mariana Trench (Figure 5; Supplementary Figure S6). In the predominant nitrite-oxidizing bacterial populations in hadal waters, Nitrospina overcame Nitrospira in the Japan Trench (Supplementary Figure S10), whereas the opposite trend has been found in the Challenger Deep (Nunoura et al., 2015). These results indicate that the

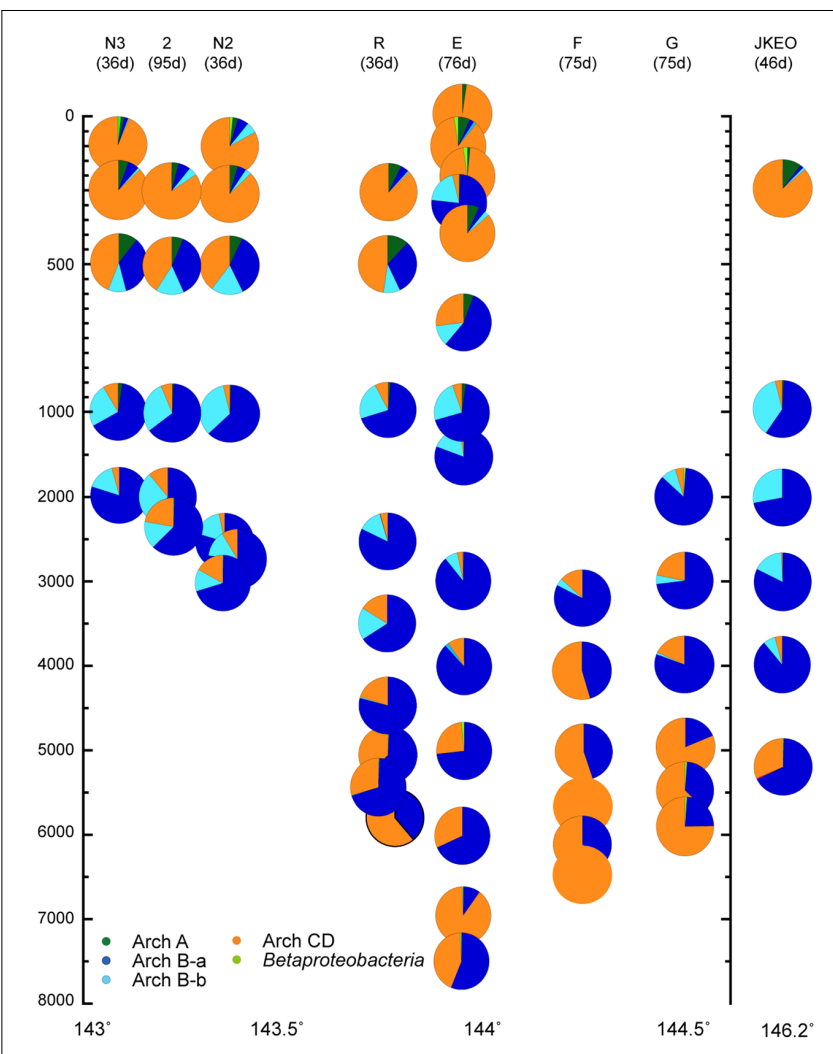

FIGURE 5 | Relative abundance of the amoA gene groups throughout the water column, as estimated by quantitative PCR in the Japan Trench region. The classification of the archaeal amoA subgroups is shown in Supplementary Figure S8. Water samples from the deepest depth for each station were taken at above $10 \mathrm{~m}$ from the seafloor. Green, blue, light blue, and orange indicate relative abundance of archaeal amoA groups $\mathrm{A}, \mathrm{Ba}, \mathrm{Bb}$, and $\mathrm{C} / \mathrm{D}$, and light green indicate betaproteobacterial amoA.

primary production in the shallow water zone significantly affects the distribution and function of microbial communities, even in much deeper waters. Nevertheless, there are many common features in planktonic microbial communities through the water columns, particularly in hadal microbial communities between the two different oceanographic regions. In both trench regions, it was observed that group $\gamma$ and group $\delta$ MGI predominantly occurred in the lower mesopelagic to abyssal waters and group $\alpha$ MGI in the hadal waters. The potential niche separation of AOA described below suggests the occurrence of higher ammonia/ammonium flux in the hadal waters than that in overlying waters. The lower relative abundance of the potential chemolithotrophic SAR324 population in the hadal waters comparing with the overlying water masses is also found as the common feature of the both trenches. Over all microbial communities in the hadal waters in both trenches would be distinguishable from the communities in the overlying waters (Figure 4; Supplementary Figure S7). Accordingly, the potential function of common mechanism(s) and geochemical cycles would lead to the development of similar hadal microbial communities in geologically and oceanographically different trench environments. 


\section{Niche Separation of Nitrifiers}

A comparison of the results of the clone and quantitative PCR analyses of the archaeal amoA genes confirmed that the archaeal $a m o A$ gene community structures obtained by the clone analysis were highly biased, as previously reported (Meinhardt et al., 2015; Nunoura et al., 2015). The coordination existed between the thaumarchaeal SSU rRNA and $a m o A$ gene clusters that were suggested by the quantitative PCR of $a m o A$ and SSU rRNA gene clone analysis: groups $\alpha$ and $\mathrm{C} / \mathrm{D}, \beta$ and $\mathrm{A}, \gamma$ and $\mathrm{Ba}$, and $\delta$ and $\mathrm{Ba}$, which is consistent with previous observations (Walker et al., 2010; Swan et al., 2014; Nunoura et al., 2015; Santoro et al., 2015).

It has been pointed out that the niche separation of nitrifier populations is primarily regulated by the availability of electron donors (Blackburne et al., 2007; Martens-Habbena et al., 2009; Sintes et al., 2013). Thus, the niche separation of nitrifiers provides a biogeochemical clue for understanding carbon and nitrogen cycles in oceanic ecosystems, thus highlighting the possible ammonia/ammonium flux/availability in oceanic ecosystems because the concentration in oceanic waters is usually too low to measure accurately. The niche separation of MGI $\alpha$, $\delta$, and $\gamma$ in bathyal, abyssal and hadal waters in Japan Trench regions (Figure 5; Supplementary Figure S6) was similar to that found in the Challenger Deep (Nunoura et al., 2015), and the results suggest that the availability of ammonium/ammonia in these deep waters are also similar. However, in contrast to the niche separation of AOA in the deep waters, a difference was found in the dominant NOB populations in the hadal waters of the trenches. The higher abundance of Nitrospina than Nitrospira suggests that the availability of nitrite for NOB associated with the hadal waters in the Japan Trench (Supplementary Figure S10) was lower than that in the hadal waters of the Challenger Deep, in which Nitrospira predominated in NOB (Nunoura et al., 2015).

In addition to the ammonia/ammonium concentration, sunlight, $\mathrm{pH}$, and salinity seem to be significant factors that affect the niche separation of ammonia oxidizers (Mosier and Francis, 2008; Gubry-Rangin et al., 2011; Merbt et al., 2012) in the shallow waters in the Japan Trench region. The salinity variation in this study was quite small $(<1.5)$ and is likely negligible throughout the water columns (Figure 5; Supplementary Figure S2). The effect of sunlight might be limited in the surface waters in this oceanic region, given the high turbidity in the shallow waters, and the presence of AOA was confirmed even in the surface water by quantitative PCR. The highest $\mathrm{pH}$ value of the water column is generally observed in surface waters, but the group $\alpha$ MGI (group C/D amoA) dominated in the AOA communities of both the surface and hadal waters. Thus, only a small impact of $\mathrm{pH}$ variation was expected in the niche separation of ammonia oxidizers in the oceanic microbial communities.

The predominance of group $\alpha$ (group C/D amoA genes) in the shallow waters in the Japan Trench region would be associated with ammonia/ammonium flux and/or sunlight irradiation. In tropical and subtropical oceans, the group $\beta$ MGI (group A amo $A$ genes) predominates in AOA communities in shallow waters (Beman et al., 2008; Santoro et al., 2015). The $\mathrm{pH}$ values of the Japan Trench region are slightly higher than those in the surface waters of tropical and subtropical regions including the Mariana Trench region (Pelejero et al., 2010).
However, significant differences are expected in the availability of ammonia/ammonium and the extent of sunlight irradiation between the eutrophic Japan Trench region and the oligotrophic tropical or subtropical regions (Sarmiento and Gruber, 2006). In fact, the presence of AOA in surface water in the Japan Trench was detected by quantitative PCR of $a m o A$ genes in this study but has not been detected in the surface water of the Mariana Trench region (Nunoura et al., 2015). In addition, the transition depth between the predominance of the HAC and LAC groups in the Japan Trench sites is estimated to be $500-700 \mathrm{mbs}$ (Figure 5), whereas it has been estimated to be 150-200 mbs in the Mariana Trench (Nunoura et al., 2015). These results suggest that higher primary production and the subsequent higher heterotrophic activity would occur in the surface waters of the Japan Trench region and that the heterotrophic microbial communities would be spread in the deeper water zones of the Japan Trench than in tropical and subtropical oceanic regions. Accordingly, it seems likely that the anomalous abundance of LAC groups (group $\mathrm{Ba}$ and $\mathrm{Bb} a m o A$ ) in the community of ammonia oxidizers at $302 \mathrm{mbs}$ at station $\mathrm{E}$ was likely associated with the anomalous distribution of an oligotrophic water mass from the Kuroshio current, as suggested by the presence of a low-salinity water mass. Considering these factors, $\mathrm{pH}$ is not likely to be the primary factor, but sunlight irradiation and/or ammonia/ammonium (and even organic matter) fluxes would significantly affect the niche separation between groups $\alpha$ and $\beta$ (groups $\mathrm{C} / \mathrm{D}$ and $\mathrm{A} a m o A$, respectively).

\section{Effects of Suspended Sedimentary Organic Matter on Microbial Communities in the Japan Trench}

The effects of suspended sedimentary organic matter in the deep waters associated with the earthquakes on the distribution and composition of planktonic microbial communities was confirmed in this study. The importance of suspended organic matter, including both sinking and suspended organic matter, in microbial communities had been indicated only in the bathypelagic waters just above the seafloor (Aristegui et al., 2009; Baltar et al., 2009). In a previous study, the suspended organic matter associated with earthquake-induced seafloor deformation (landslides and turbulent sediments) has been shown to affect the microbial cell abundance and composition of abyssal microbial communities in the Japan Trench region (Kawagucci et al., 2012). In this study, the effect of the suspended organic matter associated with earthquake-induced seafloor deformation on the viral abundance was identified, and the impact on the viral abundance was likely delayed compared to that on microbial abundance (Figure 1). In addition, the compositional changes of ammonia oxidizers' populations and other microbial components responded to the anomalous distribution of high turbidity, especially in the abyssal waters of the ocean-side slope stations (Figures 3-5). Moreover, a significant similarity of the SSU rRNA gene phylotype compositions was observed between the hadal waters of the trench axis and the abyssal waters with high turbidity (Figure 4; Supplementary Figure S3). These results indicate that the 
distinctive hadal microbial ecosystems are driven by suspended sedimentary organic matter from the trench slope, as hypothesized in a previous study of the Challenger Deep (Nunoura et al., 2015). Nevertheless, the effect of suspended sedimentary organic matter on the microbial communities is still unclear in the bathyal waters of the continental slope. The effect of suspended sedimentary organic matter on planktonic microbial communities would occur after landslide and turbulent sediment events, although we cannot accurately estimate when landslides and turbulent sediments occur or their duration. The recent landslides and turbulent sediments in the bathyal waters may result in a high turbidity water mass but do not foster planktonic microbial communities that respond to the events. Earthquake-dependent and/or -independent frequent landslides and turbulent sediments and the suspended sedimentary organic matter significantly affects the distribution, composition and function of planktonic microbial communities in trench environments and may lead to the formation and development of a distinctive hadal microbial ecosystem, together with the specific geomorphological and hydrotopographic features of trench valleys.

The methods applied in this study hindered a complete view of the planktonic biosphere in the water columns from sea surface to hadal ocean, especially in the lack of organic geochemistry and functional genomic information. In addition, we cannot excluded the possibility of the PCR biases that might influence the overview of the planktonic biosphere. We will in the future measure concentrations of organic compounds and conduct less biased molecular approaches such as metagenomics and/or transcriptomics to revel the complete view, role and functions of planktonic biosphere in deep oceans.

\section{REFERENCES}

Arai, K., Naruse, H., Miura, R., Kawamura, K., Hino, R., Ito, Y., et al. (2013). Tsunami-generated turbidity current of the 2011 Tohoku-Oki earthquake. Geology 41, 1195-1198. doi: 10.1130/G34 777.1

Aristegui, J., Gasol, J. M., Duarte, C. M., and Herndl, G. J. (2009). Microbial oceanography of the dark ocean's pelagic realm. Limnol. Oceanogr. 54, 15011529. doi: 10.4319/lo.2009.54.5.1501

Baltar, F., Arístegui, J., Gasol, J. M., Sintes, E., and Herndl, G. J. (2009). Evidence of prokaryotic metabolism on suspended particulate organic matter in the dark waters of the subtropical North Atlantic. Limnol. Oceanogr. 54, 182-193. doi: 10.4319/lo.2009.54.1.0182

Beman, J. M., Popp, B. N., and Francis, C. A. (2008). Molecular and biogeochemical evidence for ammonia oxidation by marine crenarchaeota in the Gulf of California. ISME J. 2, 429-441. doi: 10.1038/ismej.20 07.118

Beman, J. M., Sachdeva, R., and Fuhrman, J. A. (2010). Population ecology of nitrifying archaea and bacteria in the Southern California Bight. Environ. Microbiol. 12, 1282-1292. doi: 10.1111/j.1462-2920.2010.02172.x

Blackburne, R., Vadivelu, V. M., Yuan, Z., and Keller, J. (2007). Kinetic characterisation of an enriched Nitrospira culture with comparison to Nitrobacter. Water Res. 41, 3033-3042. doi: 10.1016/j.watres.2007. 01.043

Brussaard, C. P. D. (2009). Enumeration of bacteriophages using flow cytometry. Methods Mol. Biol. 501, 97-111. doi: 10.1007/978-1-60327-16 4-6_11

Chitsaz, H., Yee-Greenbaum, J. L., Tesler, G., Lombardo, M.-J., Dupont, C. L., Badger, J. H., et al. (2011). Efficient de novo assembly of single-cell bacterial

\section{AUTHOR CONTRIBUTIONS}

Onboard sample processing and analysis and observatory operations were performed by TN, YY-T, MN, SK, JM, $\mathrm{OK}, \mathrm{HM}, \mathrm{MS}$, and $\mathrm{KT}$. Cell and viral counts were done by $\mathrm{MH}$ and YY-T. Molecular analyses were conducted by $\mathrm{TN}$ and $\mathrm{MH}$. Data processing was performed by TN, TY, and YT.

\section{FUNDING}

TN was supported in part by a Grant-in-Aid for Scientific Research (B) (24370015) from the Japan Society for the Promotion of Science.

\section{ACKNOWLEDGMENTS}

We thank the captains, crew, marine technicians and science parties of the $R / V$ Mirai and $R / V$ Yokosuka (Japan Agency for Marine-Earth Science and Technology) during the MR11-03, YK11-E03, and YK11-E04 cruise.

\section{SUPPLEMENTARY MATERIAL}

The Supplementary Material for this article can be found online at: http://journal.frontiersin.org/article/10.3389/fmicb. 2016.01261

genomes from short-read data sets. Nat. Biotechnol. 29, 915-921. doi: 10.1038/nbt.1966

Cronin, M. F., Meinig, C., Sabine, C. L., Ichikawa, H., and Tomita, H. (2008). Surface mooring network in the Kuroshio Extension. IEEE Syst. J. 2, 424-430. doi: 10.1109/JSYST.2008.925982

Francis, C. A., Roberts, K. J., Beman, J. M., Santoro, A. E., and Oakley, B. B. (2005). Ubiquity and diversity of ammonia-oxidizing archaea in water columns and sediments of the ocean. Proc. Natl. Acad. Sci. USA 102, 14683-14688. doi: 10.1073/pnas.0506625102

Glud, R. N., Wenzhöfer, F., Middelboe, M., Oguri, K., Turnewitsch, R., Canfield, D. E., et al. (2013). High rates of microbial carbon turnover in sediments in the deepest oceanic trench on Earth. Nat. Geosci. 6, 284-288. doi: 10.1038/ngeo 1773

Graham, D. W., Knapp, C. W., Van Vleck, E. S., Bloor, K., Lane, T. B., and Graham, C. E. (2007). Experimental demonstration of chaotic instability in biological nitrification. ISME J. 1, 385-393. doi: 10.1038/ismej.2007.45

Gubry-Rangin, C., Hai, B., Quince, C., Engel, M., Thomson, B. C., James, P. et al. (2011). Niche specialization of terrestrial archaeal ammonia oxidizers. Proc. Natl. Acad. Sci. USA 108, 21206-21211. doi: 10.1073/pnas.11090 00108

Ichino, M. C., Clark, M. R., Drazen, J. C., Jamieson, A., Jones, D. O. B., Martin, A. P., et al. (2015). The distribution of benthic biomass in hadal trenches: a modelling approach to investigate the effect of vertical and lateral organic matter transport to the seafloor. Deep Sea Res. I 100, 21-33. doi: 10.1016/j.dsr.2015. 01.010

Jamieson, A. J., Fujii, T., Mayor, D. J., Solan, M., and Priede, I. G. (2010). Hadal trenches, the ecology of the deepest places on earth. Trends Ecol. Evol. 25, 190-197. doi: 10.1016/j.tree.2009.09.009

Kawagucci, S., Yoshida-Takashima, Y., Noguchi, T., Honda, M. C., Uchida, H., Ishibashi, H., et al. (2012). Disturbance of deep-sea environments induced 
by the M9.0 Tohoku earthquake. Sci. Rep. 2, 270. doi: 10.1038/srep 00270

Kitahashi, T., Jenkins, R. G., Nomaki, H., Shimanaga, M., Fujikura, K., and Kojima, S. (2014). Effect of the 2011 Tohoku earthquake on deep-sea meiofaunal assemblages inhabiting the landward slope of the Japan Trench. Mar. Geol. 358, 128-137. doi: 10.1016/j.margeo.2014. 05.004

Kouketsu, S., Yasuda, I., and Hiroe, Y. (2005). Observation of frontal waves and associated salinity minimum formation along the Kuroshio Extension. J. Geophys. Res. 110, C08011. doi: 10.1029/2004JC0 02862

Larkin, M. A., Blackshields, G., Brown, N. P., Chenna, R., McGettigan, P. A., McWilliam, H., et al. (2007). Clustal W and Clustal X version 2.0. Bioinformatics 23, 2947-2948. doi: 10.1093/bioinformatics/btm 404

Lozupone, C., Hamady, M., and Knight, R. (2006). UniFrac-An online tool for comparing microbial community diversity in a phylogenetic context. $B M C$ Bioinformatics 7:371. doi: 10.1186/1471-2105-7-371

Mantyla, A. W., and Reid, J. L. (1978). Measurements of water characteristics at depths greater than $10 \mathrm{~km}$ in Mariana Trench. Deep Sea Res. 25, 169-173. doi: 10.1016/0146-6291(78)90004-8

Marshall, K. T., and Morris, R. M. (2012). Isolation of an aerobic sulfur oxidizer from the SUP05/Arctic96BD-19 clade. ISME J. 7, 452-455. doi: 10.1038/ismej. 2012.78

Martens-Habbena, W., Berube, P. M., Urakawa, H., de la Torre, J. R., and Stahl, D. A. (2009). Ammonia oxidation kinetics determine niche separation of nitrifying archaea and bacteria. Nature 461, 976-979. doi: 10.1038/nature 08465

Meinhardt, K. A., Bertagnolli, A., Pannu, M. W., Strand, S. E., Brown, S. L., and Stahl, D. A. (2015). Evaluation of revised polymerase chain reaction primers for more inclusive quantification of ammonia-oxidizing archaea and bacteria. Environ. Microbiol. Rep. 7, 354-363. doi: 10.1111/1758-2229. 12259

Merbt, S. N., Stahl, D. A., Casamayor, E. O., Martí, E., Nicol, G. W., and Prosser, J. I. (2012). Differential photoinhibition of bacterial and archaeal ammonia oxidation. FEMS Microbiol. Lett. 327, 41-46. doi: 10.1111/j.15746968.2011.02457.x

Mosier, A. C., and Francis, C. A. (2008). Relative abundance and diversity of ammonia-oxidizing archaea and bacteria in the San Francisco Bay estuary. Environ. Microbiol. 10, 3002-3016. doi: 10.1111/j.1462-2920.2008. 01764.x

Noguchi, T., Tanikawa, W., Hirose, T., Lin, W., Kawagucci, S., YoshidaTakashima, Y., et al. (2012). Dynamic process of turbidity generation triggered by the 2011 Tohoku-Oki earthquake. Geochem. Geophy. Geosys. 13:Q11003. doi: 10.1029/2012GC004360

Nomaki, H., Mochizuki, T., Kitahashi, T., Nunoura, T., Arai, K., Toyofuku, T., et al. (2016). Effects of mass sedimentation event after the 2011 off the Pacific coast of Tohoku earthquake on benthic prokaryotes and meiofauna inhabiting the upper bathyal sediments. J. Oceanogr. 72, 113-128. doi: 10.1007/s10872-0150293-5

Nozaki, Y., Yamada, M., Nakanishi, T., Nagaya, Y., Nakamura, K., Shitashima, K., et al. (1998). The distribution of radionuclides and some trace metals in the water columns of the Japan and Bonin trenches. Oceanologica Acta 21, 469-484. doi: 10.1016/S0399-1784(98)80031-5

Nunoura, T., Nishizawa, M., Kikuchi, T., Tsubouchi, T., Hirai, M., Koide, O., et al. (2013). Molecular biological and isotopic biogeochemical prognoses of the nitrification-driven dynamic microbial nitrogen cycle in hadopelagic sediments. Environ. Microbiol. 15, 3087-3107. doi: 10.1111/1462-2920. 12152

Nunoura, T., Takaki, Y., Hirai, M., Shigeru, S., Makabe, A., Koide, O., et al. (2015). Hadal biosphere: insight into the microbial ecosystem in the deepest ocean on Earth. Proc. Natl. Acad. Sci. USA 112, E1230-E1236. doi: $10.1073 /$ pnas. 1421816112

Nunoura, T., Takaki, Y., Kakuta, J., Nishi, S., Sugahara, J., Kazama, H., et al. (2011). Insights into the evolution of archaea and eukaryotic protein modifier systems revealed by the genome of a novel archaeal group. Nucleic Acid Res. 39, 3204-3223. doi: $10.1093 / \mathrm{nar} / \mathrm{gkq} 1228$

Nunoura, T., Takaki, Y., Kazama, H., Hirai, M., Ashi, J., Imachi, H., et al. (2012). Microbial diversity in deep-sea methane seep sediments presented by SSU rRNA gene tag sequencing. Microbes Environ. 27, 382-390. doi: 10.1264/jsme2.ME12032

Oguri, K., Kawamura, K., Sakaguchi, A., Toyofuku, T., Kasaya, T., Murayama, M., et al. (2013). Hadal disturbance in the Japan Trench induced by the 2011 Tohoku-Oki earthquake. Sci. Rep. 3:1915. doi: 10.1038/srep 01915

Pelejero, C., Calvo, E., and Hoegh-Guldberg, O. (2010). Paleoperspectives on ocean acidification. Trend. Ecol. Evol. 25, 332-344. doi: 10.1016/j.tree.2010.02.002

Pruesse, E., Peplies, J., and Glöckner, F. O. (2012). SINA: accurate high-throughput multiple sequence alignment of ribosomal RNA genes. Bioinformatics 28, 18231829. doi: 10.1093/bioinformatics/bts252

Purkhold, U., Pommerening-Roser, A., Juretschko, S., Schmid, M. C., Koops, H. P., and Wagner, M. (2000). Phylogeny of all recognized species of ammonia oxidizers based on comparative 16S rRNA and amoA sequence analysis: implications for molecular diversity surveys. Appl. Environ. Microbiol. 66, 5368-5382. doi: 10.1128/AEM.66.12.5368-5382. 2000

Sano, Y., Hara, T., Takahata, N., Kawagucci, S., Honda, M., Nishio, Y., et al. (2014). Helium anomalies suggest a fluid pathway from mantle to trench during the 2011 Tohoku-Oki earthquake. Nat. Commun. 5, 3084. doi: $10.1038 /$ ncomms 4084

Santoro, A. E., Dupont, C. L., Richter, R. A., Craig, M. T., Carini, P., McIlvin, M. R., et al. (2015). Genomic and proteomic characterization of "Candidatus Nitrosopelagicus brevis": an ammonia-oxidizing archaeon from the open ocean. Proc. Natl. Acad. Sci. U.S.A 112, 1173-1178. doi: 10.1073/pnas.14162 23112

Sarmiento, J. L., and Gruber, N. (2006). Ocean Biogeochemical Dynamics. Princeton, NJ: Princeton University Press.

Sheik, C. S., Jain, S., and Dick, G. J. (2014). Metabolic flexibility of enigmatic SAR324 revealed through metagenomics and metatranscriptomics. Environ. Microbiol. 16, 304-317. doi: 10.1111/1462-2920.12165

Sintes, E., Bergauer, K., De Corte, D., Yokokawa, T., and Herndl, G. J. (2013). Archaeal amoA gene diversity points to distinct biogeography of ammoniaoxidizing Crenarchaeota in the ocean. Environ. Microbiol. 15, 1647-1658. doi: 10.1111/j.1462-2920.2012.02801.x

Spieck, E., Keuter, S., Wenzel, T., Bock, E., and Ludwig, W. (2014). Characterization of a new marine nitrite oxidizing bacterium, Nitrospina watsonii sp. nov., a member of the newly proposed phylum "Nitrospinae.". Syst. Appl. Microbiol. 37, 170-176. doi: 10.1016/j.syapm.2013.12.005

Stephen, J. R., Chang, Y. J., Macnaughton, S. J., Kowalchuk, G. A., Leung, K. T., Flemming, C. A., et al. (1999). Effect of toxic metals on indigenous soil beta-subgroup proteobacterium ammonia oxidizer community structure and protection against toxicity by inoculated metal-resistant bacteria. Appl. Environ. Microbiol. 65, 95-101.

Swan, B. K., Chaffin, M. D., Martinez-Garcia, M., Morrison, H. G., Field, E. K., Poulton, N. J., et al. (2014). Genomic and metabolic diversity of marine group I thaumarchaeota in the mesopelagic of two subtropical gyres. PLoS ONE 9:e95380. doi: 10.1371/journal.pone.0095380

Swan, B. K., Martinez-Garcia, M., Preston, C. M., Sczyrba, A., Woyke, T., Lamy, D., et al. (2011). Potential for chemolithoautotrophy among ubiquitous bacteria lineages in the dark ocean. Science 333, 1296-1300. doi: $10.1126 /$ science. 1203690

Taira, K., Kitagawa, S., Yamashiro, T., and Yanagimoto, D. (2004). Deep and bottom currents in the challenger deep, measured with super-deep current meters. J. Oceanogr. 60, 919-926. doi: 10.1007/s10872-005-00 $01-\mathrm{y}$

Taira, K., Yanagimoto, D., and Kitagawa, S. (2005). Deep CTD casts in the challenger deep, Mariana Trench. J. Oceanogr. 61, 447-454. doi: 10.1007/s10872-005-0053-z

Takai, K., and Horikoshi, K. (1999). Genetic diversity of archaea in deep-sea hydrothermal vent environments. Genetics 152, 1285-1297.

Takai, K., and Horikoshi, K. (2000). Rapid detection and quantification of members of the archaeal community by quantitative PCR using fluorogenic probes. Appl. Environ. Microbiol. 66, 5066-5072. doi: 10.1128/AEM.66.11.5066-5072. 2000

Walker, C. B., de la Torre, J. R., Klotz, M. G., Urakawa, H., Pinel, N., Arp, D. J., et al. (2010) Nitrosopumilus maritimus genome reveals 
unique mechanisms for nitrification and autotrophy in globally distributed marine crenarchaea. Proc. Natl. Acad. Sci. U.S.A 107, 8818-8823.

Wertz, S., Poly, F., Le Roux, X., and Degrange, V. (2008). Development and application of a PCR-denaturing gradient gel electrophoresis tool to study the diversity of Nitrobacter-like nxrA sequences in soil. FEMS Microbiol. Ecol. 63, 261-271. doi: 10.1111/j.1574-6941.2007. 00416.x

Yilmaz, P., Parfrey, L. W., Yarza, P., Gerken, J., Pruesse, E., Quast, C., et al. (2014). The SILVA and "All-species living tree project (LTP)" taxonomic frameworks. Nucleic Acids Res. 42, D643-D648. doi: 10.1093/nar/gkt 1209
Conflict of Interest Statement: The authors declare that the research was conducted in the absence of any commercial or financial relationships that could be construed as a potential conflict of interest.

Copyright (c) 2016 Nunoura, Hirai, Yoshida-Takashima, Nishizawa, Kawagucci, Yokokawa, Miyazaki, Koide, Makita, Takaki, Sunamura and Takai. This is an openaccess article distributed under the terms of the Creative Commons Attribution License (CC BY). The use, distribution or reproduction in other forums is permitted, provided the original author(s) or licensor are credited and that the original publication in this journal is cited, in accordance with accepted academic practice. No use, distribution or reproduction is permitted which does not comply with these terms. 